\title{
Growing old in an information society
}

\author{
Marc van Lieshout*, Thea Weijers** and René van Rijsselt*** \\ * Rathenau Instituut, P.O. 85525, NL-2508 CE The Hague \\ Phone: +3170 3421501; Fax: +31703633488 \\ Email:m.vanlieshout@Rathenau.KNAW.nl \\ or:marcvl@cs.kun.nl \\ ** TNO-STB, P.O. 541, NL-7300 AM Apeldoorn \\ Phone: + 3155 5493497; Fax: + 31555421458 \\ Email: T.Weijers@stb.tno.nl \\ *** Department of Sociology and Social Gerontology, Free \\ University, De Boelelaan 1081C, NL-1081 HV Amsterdam \\ Phone: +3120 4446784; Fax: + 31204446810 \\ Email:RJT.v_Rijsselt@scw.vu.nl
}

\begin{abstract}
The societal implications of electronic highways receive more attention than some years ago. Still, it is not sure whether the debate that has started contains more than cheap rhetoric. The Dutch Rathenau Institute has initiated a project to research the images and perspectives that important stakeholders have about a very specific group on the electronic highways: elderly people. The project was aimed at providing insights into the position of elderly people in the information society: are they included or excluded? In this paper, attention is focused on the role and position of elderly people as citizens: negotiating with public authorities, having rights and fulfilling obligations by means of information and communication technologies. It is argued that elderly people might need specific attention when it comes to the question whether they are 'in' or 'out'. The variety in elderly people prohibits too many broad statements, though some remarks can be made concerning their shared history, educational style, and age.
\end{abstract}




\section{INTRODUCTION}

In the Netherlands, the Rathenau Institute (the successor of the former Dutch Organization for Technology Assessment - NOTA) initiated in 1996 a project dedicated to the question whether the pronounced concerns about the division between the 'Information Rich' and the 'Information Poor' entail more than the rhetoric they seem to be based on. A number of questions were phrased. What precisely are the arguments underlying the concerns? To what kind of visions, perspectives or expectations do they refer? Is there reason to believe that the visions are shared among relevant actors? Are the actors who are formulating the visions in which exclusion processes are present, able to articulate where these processes stem from? The project was meant to offer a reflection on the problem of exclusion that - according to some - might follow the widespread introduction of electronic highways. In that sense, the project was an assessment. It was, however, not a traditional Technology Assessment (TA). In line with the mission statement of the Rathenau Institute the traditional TA-approach has been exchanged for a broader approach that takes socio-cultural changes as a starting point, assuming that technological developments are embedded in socio-cultural practices.

In this paper, we will discuss the results of this project. We will particularly tackle the question of how the position of elderly people as citizens within the information society may change due to the informatization of society. We will start with a brief sketch of the motivation for the project and the choice of the category of elderly people. Then, a brief description of the theoretical model we used will be presented. The core of the article will be the presentation of our findings with respect to the elderly citizen in the information society. We will conclude with a discussion of the main results.

\section{SPOTLIGHT ON ...}

In tackling the question of whether processes of social exclusion are part of the contemporary diffusion of electronic highways, the focus must be oriented towards a specific demographic category. Posing the question too broadly leads to superfluous answers on non-existing problems. The change processes that are experienced in modern - western - societies lead to different problems and to different problem definitions for different social categories. Socio-economic stratifications might be a starting point to delineate groups of interest. With respect to the electronic highways it is commonplace to propose that only White Higher educated Young Male People (WHYMP) profit from the digital revolution. Women, lower educated people, the elderly, and foreigners or immigrants experience difficulties in mastering the technology and its applications. This, however, is an approach that takes the Internet and its early adopters as representative of the electronic highways and their riders. Though the Internet today undoubtedly determines many of the popular images about what the information society will look like, it would be a mistake to take that perspective too seriously. We take the electronic highways (the Internet included) as a metaphor for the process of informatization of society. This informatization is, for the time being, the sum total of processes of socio-cultural change in which 
political, economical, juridical, social, and technological problems seem somehow to correlate to the gathering, processing, and distribution of information.

Taking this process of informatization as a starting point, the problems that specific categories of people may experience may be more encompassing than just the problem of knowing how to connect a personal computer to the Internet.

After a small survey, the Rathenau Institute decided to take elderly people as the focal group within the project. A number of arguments led to this choice.

The ageing of society is a well studied phenomenon. In the Netherlands, some 3.4 million people are aged 55 or older (from a total population of roughly 15 million). Of this group, two million are aged 65 or older. Dutch society is confronted with a double greying process: the absolute as well as the relative proportion of elderly people (aged 55 years or older) will increase dramatically in the decades to come, while there will also be an increase in people aged 80 years or more (most of the last category will be widowed women).

Elderly people together own many of the financial resources in society. In $1989,7 \%$ of people aged 65 or older had personal financial resources of at least 100,000 ECUs (compared with an overall percentage of $4.7 \%$ of the population). This wealth, however, is unevenly distributed. Especially those elderly people above 80 years or more - most of them widowed women who together do not form a very big group - do not have much money to spend. Many households with only one person (usually a woman) have incomes that do not exceed social minimum standards (Timmermans, 1993, pp. 14-24; Timmermans, 1997, pp. 72). Terms such as the silver generation are used to denote the average wealth of today's older people. But, it should be noted that this silver generation will not exceed $25 \%$ of the total aged community, while another $50-60 \%$ will have very limited financial resources (Timmermans, 1997, pp. 76-77).

Another argument for taking elderly people as the main group to be studied is the fact that, while elderly people seem to have longer and better lives than a few decades ago, their societal role is still very restricted. The composition of elderly cohorts will drastically change in the years to come, hinting at a built-in conflict between the societal role they are assigned to and their needs and desires in this respect (the so-called 'structural lag'). As past participants in the democratization processes of the 1960s and 1970s, it is highly unlikely that the future elderly will accept a societal position at the margin. The beginnings of this transition are visible now. Elderly people organize political parties, they empower their representatives. In the last elections, two parties that presented themselves explicitly as political parties of elderly people were elected to parliament. The political pressure of elderly parties might increase in the years to come. The societal tension between the images and roles attributed to the elderly and the positions they want to have themselves, could be studied as an effect of ongoing changes due to the informatization of society.

A last argument is the fact that elderly people are faced with many, negative, stereotypes. It is said that they should be unable to pick up the latest technological developments and, even if they can, they are unwilling to do so. They experience physical problems that forbid them to remain active, they are unable to cope with the speed of contemporary life, etc. Many of these stereotypes lack any solid foundation. Still, they are widespread and are often used in documents and in policy-making. 


\section{RESEARCHING PERSPECTIVES - HOW TO APPROACH THE ELDERLY CITIZEN?}

A research panel was formed that was willing to take responsibility for the project. The authors were - in different roles - part of the panel. A theoretical framework was developed that guided the empirical part of the project. The second step was the organization and collection of empirical findings. This was done in two subsequent phases: the first was the diversification phase, in which as many different perspectives as possible were collected; the second phase was aimed at realizing convergence among the formulated perspectives. Finally, a report was written that combines the theoretical model and the empirical findings.

In this section, we describe the theoretical model we used, the societal domains we studied, and the research method.

\section{The theoretical model}

The starting point of the model was its ability to identify forms and mechanisms of exclusion processes. Within the Department of Social Gerontology of the Free University of Amsterdam, sociological research dealing with the process of ageing is part of the usual activities of the research group. The model that forms the core of the department's activities looked to be very useful for our purposes (Onderzoekprogramma, 1995). Basic to the model is the level of independency an individual has in his or her living surroundings. This independency has three distinct features: the level of self-determination, the level of self-care, and the level of societal participation. The first relates to the ability to decide for oneself what to do and how to behave. The second relates to the ability to take care of oneself in daily situations (cooking, cleaning, washing, dressing, and the like). The third relates to the ability to participate in clubs, groups, political parties, public debates, and so on.

Processes of exclusions are defined as occurring as a result of the mismatch between pressure exerted on individuals through channels that link individuals with their surroundings and their individual competencies. The competencies are analytically split up into abilities, restrictions, and potentialities. Exclusion may be found or determined by a diminished self-determination, self-care, societal participation, or a combination of the three. It may be typified by the following four mechanisms: don't have to; don't want to; are not able to; are not allowed to.

Having presented the socio-gerontological basis of the study, we can now tackle the question of how informatization should be included in the model. The notions from socio-gerontology were mixed with notions from technology researchers such as those from the Organization for Applied Scientific Research, Centre for the Study of Technology Policy (TNO-STB). Processes of informatization will be found on two levels: first, as part of the outer spheres, as processes exerting influence on individuals in a variety of ways (organizational, economic, technological, etc.); second, as part of the individual's competencies, that is, the potentialities, restrictions, and aspirations of the individual. Informatization is a fluid concept. It relates to the introduction of networks in working situations, but also to the reorganization of activities due to the 
opportunities information and communication technologies (ICT) offer. Like all technologies, ICT has a hard and a soft component. The hard part refers to the artifacts, like computers and network infrastructures, but also to computer software and network protocols, i.e., the organization of the environment. The soft part refers to the knowledge and the skills that are needed to use the artifacts, i.e., the competencies of the individual. Informatization is a process in which ICT are used to rearrange and to redefine existing social structures and patterns by referring to the gathering, processing, and distribution of information.

Figure 1. Theoretical framework 'Exclusion of elderly people'

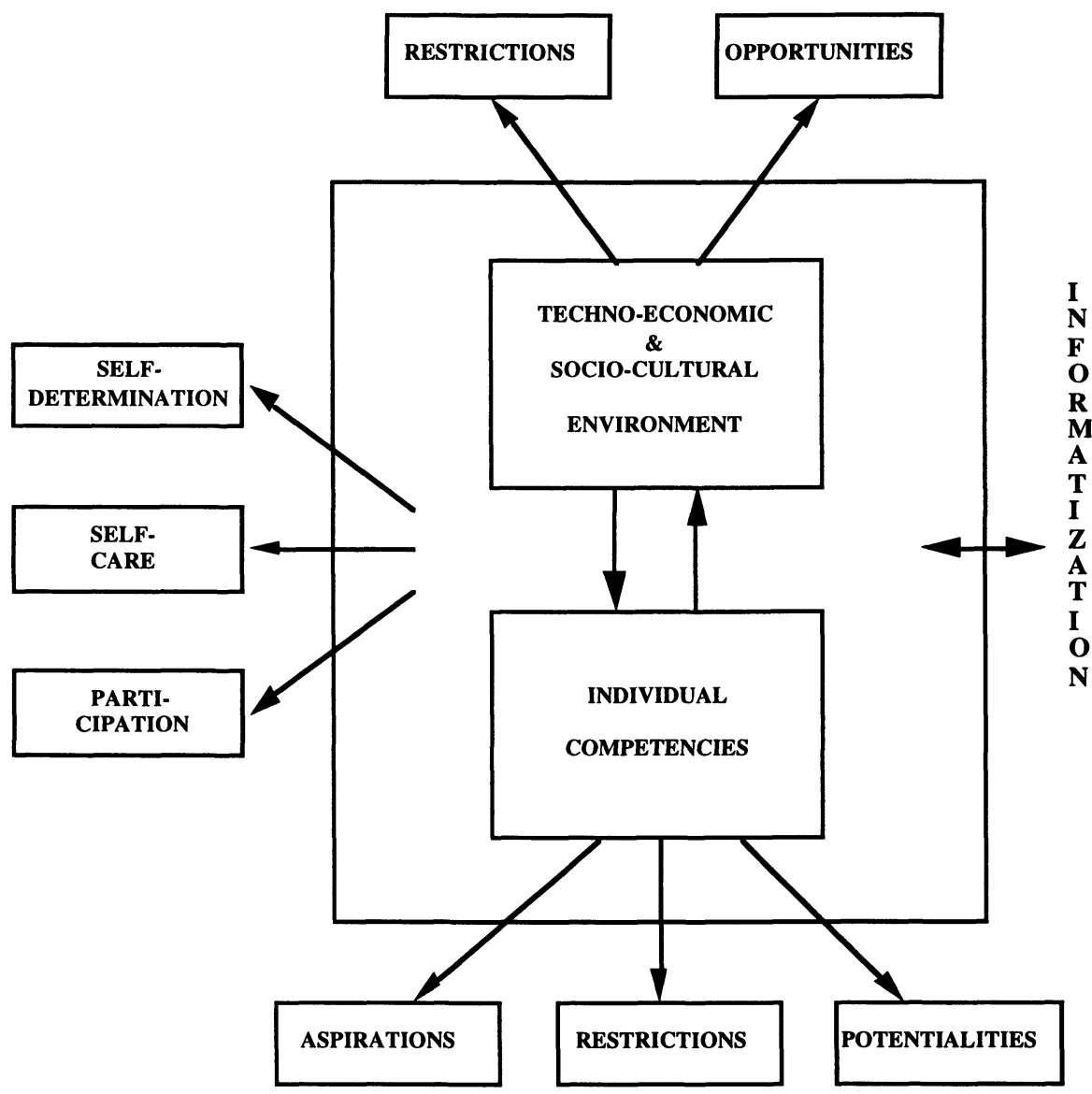

Views and perspectives on informatization will differ in their focal point: will they relate to processes in technological developments, to processes in economic structures, or to processes of socio-cultural dimensions? In our model we analytically discriminated between the techno-economic domain and the socio- 
cultural domain. Visions about the future information society usually include aspects of both domains. Bringing these components together in one framework leads to the model presented in Figure 1.

\section{Societal domains of interest}

Having formulated the theoretical approach, we had to decide which societal roles of the elderly should be part of the research. The heterogeneity of the conglomerate of the elderly suggests that different people may experience different kinds of pressures, while having different sets of competencies. Because the project was aimed at identifying societal mechanisms and forms of exclusion processes we decided to identify different societal domains that might be important in terms of our research objectives.

One of the most important aspects of societal participation is being part of the labour force, being employed, having a job. The Dutch situation on the labour market is rather peculiar with a very high rate of exclusion of elderly people. In the past two decades, roughly $50 \%$ of employees aged 55 or older retired. It should be mentioned that originally attractive financial arrangements were offered to encourage elderly people to retire. Today, these arrangements are questioned: they are costly and the expulsion of the elderly from the labour market is seen as apt to discriminate on the basis of age. The effect of ICT on the organization of work, in a quantitative as well as a qualitative sense, is a highly debated issue. The fact that there have been profound changes is not disputed. The role that informatization plays in these processes of change, especially when analyzed from the perspective of a specific category of workers, is not clear. The changing composition of the working force, the changes in work processes, and the changing requirements with respect to work satisfaction, together inspired us to look for processes of exclusion in this domain.

ICT, the Internet, the electronic highways, virtual reality, and all the other buzzwords, somehow seem to relate more to younger people than to the elderly. Today's culture is a youngster culture. Being old is out. Products and services are developed and presented with reference to qualities of youth: they have sex-appeal, they fit in a fast and speedy culture, they look good, etc. Products or services specifically developed for the elderly are dull, boring, clumsy, slow, big, grey, and so on. Companies avoid being associated with elderly customers. Their reluctance is based on stereotypical images of elderly people. But, even elderly people themselves seem to take these stereotypes for granted. These attitudes made the domain of the elderly consumer an interesting domain to research.

The third and final perspective related to societal participation is in the sense of being a citizen, being able to exert your civilian rights, fulfilling your civilian obligations, and being able to deal with administrative and bureaucratic procedures.

In each of these three domains, different processes in which informatization plays a role can be identified. The socio-technical dynamics within each domain follow different routes, have different value-systems and pose different kinds of questions about the impact of informatization on elderly people. 


\section{The research method}

Two phases were formulated in the project: a divergence phase in which as many perspectives as possible were collected, and a convergence phase in which the similarities and differences between the perspectives were identified. The first phase was organized in three separate sessions, following the three societal domains. The method used in the first phase was the method of a - non-public - hearing. During three days, some 24 different actors were interviewed.

The results of the hearings were analyzed in view of the theoretical framework, and were presented in an evaluation report (Van Rijsselt and Weijers, 1997).

In a working conference, we checked out our findings. Apart from the 24 interviewees, another 15 experts were invited to participate. The results of the working conference were combined with our earlier findings. At the time of writing this paper, the researchers on the panel are in the process of writing the final report (Van Rijsselt and Weijers, 1997b).

\section{THE ELDERLY CITIZEN IN THE INFORMATION SOCIETY}

All three domains showed intriguing features with respect to the role and position of the elderly. We will use this paper to concentrate on the third domain: the domain of the elderly citizen. Of all the three fields, this field is most affiliated with an on-going concern of the Rathenau Institute: the debate over the restructuring of the public domain.

ICT applications fulfil a number of functions. An important one is the supply of electronic channels to get informed. Concepts such as the information society underscore the importance of information in contemporary society. The economic importance of information and information-related processes (like logistics) has led to the announcement of the successor of the industrial society: more than $60 \%$ of gross domestic product stems from information-related activities, and more than $60 \%$ of workers are information workers (Dordick and Wang, 1993). The second function is communication. Both information and communication are reflected in the acronym, ICT. Next to these two core functions of ICT, the opportunities for offering transaction facilities (like electronic banking or reservation of tickets) and entertainment (video-on-demand and games) are usually seen as important driving forces for the diffusion of ICT. In the following paragraphs, we will concentrate on the two main aspects of ICT, as reflected by its name: information and communication. To indicate the effect of the latter, we add the term 'participation' to the term 'communication', promoting our opinion that communication is the tool to enable participation.

\section{Information over, for, and by elderly people}

In a politico-administrative research project developments in administrative reorganization processes and information and communication technologies (ICT) were analyzed (Zuurmond, 1994). Two ideal types of informatization were sketched (ideal type in the Weberian sense of 'a unified conceptual approach to an analysis of both subjective meaning and structural forms' (Zuurmond, 1994, p. 14): the 
global and universal informatization and the local and contextual informatization. Global and universal informatization refers to bureaucratic elements like standardization, formalization, centralization, hierarchization, and specialization. The control of the specific uses of ICT in an organization remains with the uppermost, highest level. Global and universal informatization fits in a hierarchical context, with a top-down structure, and a command and control regime. Local and contextual informatization refers to the non-bureaucratic uses of ICT on the workfloor where personal preferences, flexibility, creativity, individual responsibility, and output-oriented tasks are supported by organizational and networked intelligence provided by computers and networks. This kind of informatization fits more in an egalitarian approach with a bottom-up structure and a networked structure where command and control is not exerted from a fixed centre but is distributed within the network. The empirical research of Zuurmond showed that it is not the latter use of ICT that is at hand. The Weberian bureaucracy is strengthened by new ICT. The specific uses of ICT reflect the norms and values of higher management, and reflect such organizational requirements as efficiency, speed, reduced throughput times, and reduced stocks. The norms of the local and contextual informatization, on the other hand, refer to issues like customer-oriented approaches, personalized services, quality of services, and an integral work approach instead of division in routinized and non-routinized tasks. It was shown that, at present, it is still the norms of higher management that are implemented in the use of new ICT.

Whether this result should be seen as the final outcome of the process of informatization from the last two decades, or as part of a transition period that finally will give the benefit to the more egalitarian approach, is an open issue. Activities that have been initiated by public authorities in recent years contain both approaches, and seem to be based on a mix of both normative schemes. We will discuss a few of them in the following.

Public authorities have initiated a number of activities around so-called civic service centres: one-stop shopping centres where citizens do not have to wonder which sequence of counters has to be followed in order to get information, to deposit a complaint or to renew a driving license. In a one-stop-shopping approach, the citizen's comfort seems to be increased because any administrative burden is shifted to the back-office and is supplanted by intelligent computers. In the Netherlands, an initiative has been launched by the Department of Internal Affairs, in which municipalities are invited to develop projects for developing and implementing one-stop shopping counters. One interest group is the combined group of elderly and disabled people. In several municipalities, initiatives are formulated around the development of information services to the elderly and/or disabled citizens.

Several problems surround these initiatives. First, the mixture of elderly and the disabled is a rather peculiar mix of demographic variables that leads to negative labelling processes on both sides. In general, the elderly are not disabled, just as disabled people are not elderly.

Second, not much is known about specific information requests from elderly people. In general this is because elderly people were never asked what kind of services they needed (but services were simply offered on the basis of previous experiences with uses of services by elderly people). 
Third, though the number of proposals for starting a one-stop shopping centre was unexpectedly high, and showed, among other issues, a shared interest in these kinds of socio-technical innovations, many of the initiatives were part of a business redesign process that was aimed at an overall quality improvement (in line with increased efficiency, increased throughput times, increased speed of production, etc): the global and universal form of informatization.

So, while these initiatives could contribute to a strengthening of participatory functions, such as the use of facilities and being informed about need-to-know issues, in practice these functions do not seem to be at the core of the initiatives so far. The use of ICT seems to be more oriented to fulfilling internal organizational objectives, to preventing misuse of facilities (instead of stimulating the use of proper facilities), to supporting organizational changes, or to showing that public authorities are at the leading edge of developments, use the latest technologies, and belong to the category of early adopters at the cost of opportunities for the late adopters. Tentatively, we would argue that the more egalitarian approach that is visible within the initiatives legitimizes the more hierarchical one; both are based on a legitimate attempt to improve the communication between public authorities and citizens but, where the more egalitarian approach is aimed at improving the position of the citizen with respect to the local authorities, the second is aimed at improving the distribution of financial and social resources among those who are entitled to them.

A number of examples illustrate this argument. At the working conference, it was noticed that the commercial sector is more sensitive to unarticulated needs from the market. A big information-collecting organization in the Netherlands, the Air-miles organization, every three months informs roughly three million individuals about the data collected about them during these months. Use of ICT to inform citizens actively about registered information by public authorities is so far unknown. Another example of what may be called a flawed use of ICT in serving citizens is in the attribution of certain subsidies. When citizens want to apply for individual rent subsidies, they have to take the appropriate action by themselves. Meanwhile, all the information about attributing rent subsidies automatically is available to the local authorities. Similar cases were mentioned with respect to collecting any information about the changed personal situation of elderly people, where the needed information was available but not used.

A last example is the Dutch interdepartmental programme Elderly people and the electronic highway (Willems and Van den Wildenberg, 1996). This is a programme that has only recently been initiated. Its primary objective is to promote the independence of elderly people in line with the general policy for the aged. As an important way of promoting the participation of elderly people, it formulates the existence and feasibility of educational and promotional activities. This activity was viewed by the organization of the elderly as of great importance for the empowering of the elderly, in order to get them in touch with new technological developments and enable them to judge these developments on their significance. But then, the report argues that education and promotion activities fall outside the scope of the programme objectives. The programme focuses on combining information services on the supply side by creating a shopping site. It concentrates on stimulating the development of specific services for elderly people. In short, it promotes the market, and not the user. 
All these factors relate to information, provided for or over elderly people. The line of information by elderly citizens is hardly developed, not to say almost absent. There are scarcely any initiatives initiated by public authorities where citizen panels are used to support public authorities. The website SeniorWeb initiated by the Dutch Platform for Aged and Europe (NPOE) - is an example of an activity initiated by an organization of elderly people. SeniorWeb is a Dutch clone of the American SeniorNet. The NPOE tries to connect as many elderly people as possible to on-going developments in a globalizing world and as such plays a leading role in the world of the elderly ICT user. The initiative might increase awareness by political decision-makers and public authorities for the needs and interests of elderly people on the electronic highways.

\section{Communication and participation}

In general terms, societal participation decreases with age. First, elderly people stop working. Having a job relates to being in a cordial environment with people who share the same interests, belonging to a group with shared objectives, and to feelings of self-esteem. But it also relates to getting in touch with new, technological developments, like personal computers, word processors, and the like. The Netherlands has had a policy of 'Young for Old'. Faced with an enormous increase in young people entering the labour market at the beginning of the $1980 \mathrm{~s}$, it became common practice to replace older employees with younger people. In line with the aforementioned images of exclusion, it started with the elderly don't have to work, which after a while became they don't want to. The dynamics behind this shift in attitude are interesting to discuss, but fall outside the scope of this paper. The Dutch approach has led to a situation in which more than $90 \%$ of Dutch workers retire before they are 65 . Higher educated people work longer than lower educated. Higher educated people thus keep in touch longer with new developments. This is not to say that work is the only place to get in touch with new technologies, but it is a place where new technologies may be introduced as part of normal practice.

The second reason for the decrease of participation is that older people are expelled from positions of political power. Reaching the age of 70 used to imply that political or administrative positions had to be renounced. Recently, the Dutch Department of Social Affairs is engaged in preparing a law that prohibits discrimination on the basis of age in the case of getting a job. Whether this will lead to a substantial increase in elderly politicians remains to be seen. For the time being, the participation of elderly people is restricted to participating in clubs and organizations and in volunteer work. The level of organization of the elderly is pretty high in the Netherlands: organizations for elderly people have as many as 650,000 elderly members, from a total of two million people aged $65+$. Active participation remains until the age of 70-75. So, while the formal and political participatory channels are blocked, the informal and private ones are very vividly used until a reasonable age (Timmermans, 1997).

What remains to be shown is whether informatization contributes in a positive or in a negative way to the societal participation of elderly people. This is not an easy task. Empirically, this relationship is not well studied. Not much is known, for instance, about the use and appreciation of ICT tools and processes. 
An American survey among elderly people shows that $29 \%$ of Americans aged $55+$ claim to own a personal computer. The survey was held at the end of 1995 . A survey in July 1994 gave a total of $21 \%$ owners, indicating an increase of $41 \%$ over a year and a half. But items such as a video cassette recorder (VCR) (81\%) and cordless telephones $(58 \%)$ are also found regularly in elderly households (Adler, 1996). A Dutch study in Rotterdam showed that $63 \%$ of elderly people (55+) had heard about the Internet (compared with $85 \%$ of the total population). But knowledge about Stadstext-interactive (City-text, a local interactive news bulletin board on television) was almost absent (0.5\%), compared to an average acquaintance of $40 \%$ of the total population. Though many of the elderly had heard of the Internet, they did not use it. With respect to personal computers, $19 \%$ of aged Rotterdammers possess a personal computer (PC), and 4\% own a PC with modem. Overall results for the Rotterdam population were $43 \%$ and $16 \%$ respectively (Kanters and Hartkamp, 1995). In the feasibility study mentioned before (Elderly people and the electronic highway), written on the order of the interdepartmental working group The elderly and technology, a figure of $18 \%$ is mentioned for PC-owners in the age range of 55 to 70 , of whom roughly $20 \%$ owns a modem. Not more than 10,000 elderly PC-owners (aged 55-70 years) should be seen as users of the Internet (Willems and Van den Wildenberg 1996, p. 5).

These figures are difficult to relate to potentialities, restrictions, and aspirations of the elderly with respect to electronic communication. Possessing a PC is not necessarily an indication of familiarity with the use of the communicative functions of the PC. The interviews we held gave some perspectives on these items. First, with age, physical and cognitive restrictions grow. Up till the age of 75-80, however, elderly people have many mechanisms to compensate for cognitive and physiological decline. Electronic communication tools (like email) could contribute to overcoming physical as well as cognitive restrictions. Letters may be written in several steps, shopping lists may be easily filled in.

Due to our research method, we have not been able to track down the aspirations of elderly people with respect to the use of ICT. We will stick to a few general remarks.

To start with, elderly people do not reject new technology because it is new technology. They should be seen as critical users. They are eager to accept new tools when these tools can be shown to have a functional added value. Tools like security cameras and lifelines illustrate the potentialities of new technologies. But, while these tools are shown in the context of the care-needing elderly person, the biggest part of the elderly population is interested in the same kind of things as other people, like information about travelling and trips, communication about hobbies, daily news, etc. The growth of the number of elderly people with a PC might be a point in this respect. It is, however, necessary to raise awareness for the functions of the new ICT media. A very considerate and dedicated approach will be needed, since many of the relative advantages that the new media seem to offer to the young do not fit into the schemata of the old (like saving time, or avoiding places that may lead to unwanted social contacts).

With respect to potentialities, there are hardly any signs that elderly people are not able to cope with the new ICT tools, compared to other age-related groups. Information processing capacities reduce, while interpreting capacities (context- 
related acting) improve. Several interviewees noticed the problem elderly people have when they need to programme an apparatus; programming a VCR, using an automated ticket machine at the railway station, or programming the more advanced functions of a telephone pose problems.

An interesting explanation for these missing capacities is the notion of 'technology generations', hinting at the fact that everyone grows up with a very specific view of technology. Mental models are created in childhood with respect to how technology works. New technologies are viewed from these old perspectives. The flexibility of today's ICT is difficult for the elderly to understand. They were raised with machinery that was operated by means of handles and sticks; instructions had fixed sequences; changing instruction A with instruction B might have had very damaging consequences. Many elderly people lack the educational training to engage themselves in a situation of learning by doing. Today's ICT is much more fault-tolerant: the PC does not break down when improperly used. These malleable and flexible ICT tools work, however, in a far more complicated world than the world of a few decades ago. For elderly people, the difference between the speed of today's societal processes (from traffic to bureaucratic procedures) and the multi-faceted character of many processes based on modern technology may cause blockages that are hardly seen at all by younger people.

Whether the concept of technology generation is a proper concept to explore differences between the attitude of different generations towards socio-technical innovations is still an open but interesting question.

Next to the individual competencies, environmental characteristics play a role in promoting or preventing participation. First, ICT is - in a very specific sense an individual technology. Tools like PCs, and the interfaces between computers and machines, are individually based; they presuppose one person a time. Getting money from an automated teller machine (ATM), or searching information in an electronic database, is an individual man-machine process. Within this individuality, it is the user that must trigger the process. Getting a ticket from a railway station or asking for information at an automated help desk in a public place presupposes an active role and attitude from the (older) user. Today's elderly people (aged 75+) have missed this transition to an active and participative role. Their self-image reflects a passive nature: being taken care of, and being dependent on helping institutions. This places them in a backward position and shows the need for more attention to their specific situation. The elderly people aged 55-75 will, in general, have passed by higher educational levels that might support them in bridging the transition.

Second, from a more global point of view, processes of liberalization, deregulation and individualization run parallel with informatization processes. The collective arrangements of the welfare state are supplanted by individual arrangements without a general social-serving system underneath. Individuals negotiate their specific situation with employers, public authorities, insurance companies, etc. Issues like the expected disappearance of cohesion and solidarity within society, the fragmentation of traditional norms and values and the multicultural composition of contemporary society, are easily related to the global dimensions of the informatization processes. These global processes are part of the modern world: the world that is formed by the stakeholders of today. These stakeholders are everyone except the elderly whose role is limited to a wait-and-see 
attitude. It is not an easy task to engage the older community in these processes. Of course, we might question the need for empowering, engaging, and teaching the elderly. When no specific requests are heard from this group, why bother? Taking our starting point seriously - i.e. promoting independency - offers one argument for taking initiatives. Another argument is of a more opportunistic nature. Today's men and women aged 50-60 will be tomorrow's elderly of 60-70 years. Their relative and absolute size makes them an interesting target group for marketeers. Their growing political awareness makes them a group to be aware of. Within less than a decade they might become a serious political, commercial, and societal factor within society.

\section{CONCLUSION}

The project was aimed at identifying the dynamics of exclusion of elderly people in various societal fields. The exclusion process itself was split up in several dimensions, in order to develop a more sophisticated approach (Van Rijsselt and Weijers, 1997). Each dimension can be characterized by one of the following questions. On which societal domain does exclusion occur? What kind of exclusion occurs (is it the effect of a collective societal norm or is it a free and individual choice)? Is the exclusion permanent or temporary? Is it integral or partial? Is it an active form of exclusion (active denial of rights) or passive? And finally, though exclusion has a negative tone, it need not be the result of a negative process but it may be self-chosen and self-wanted.

Confronting these dimensions with the theme of this paper, we conclude that within the societal domain we focused on, the exclusion process is not integral but covers certain areas (work, politics), that exclusion is the result of a collective societal norm (we impose and endorse a view in which elderly people are allowed to withdraw from societal activities), and that it is the result of an active process (having reached the age of 65 means a formal end to a working career). Whether the exclusion is permanent or not is difficult to answer. In a sense it is (formal work, political power positions). But many initiatives - from the elderly themselves, and also from commercial players and public authorities - are launched and developed that are directed at engaging elderly people in a variety of societal processes. Elderly people themselves take up other activities that confront them with ongoing changes in society and that bring them into contact with new uses of ICT. The young elderly especially show a rather active pattern of various societal activities that enables them to keep track of new developments. The last dimension - self-chosen versus imposed exclusion - is an interesting one. We have found no signs that opposition to informatization processes grows among older people. An increasing awareness of the absence of societally significant roles for elderly people in combination with a continued hierarchical form of informatization might however lead to growing opposition, and might lead to the rise of elderly Want Nots.

We have presented arguments for the thesis that elderly people should not be treated as one single homogeneous group. The concept of technology generation has been introduced - though in a rather primitive fashion - to indicate the effect of the specific technologies with which people are raised. Then, we indicated the effect 
of the educational level and the awareness for a learning by doing attitude. Both arguments are only indicative, but nevertheless supportive, of the diversification among the elderly people.

We would like to make a final remark. Most of the processes mentioned before are not exclusively typical of elderly people. Of course, socio-cultural change processes are more global in scope, but also on the level of individual competencies we have tried to show that the aspirations, restrictions, and potentialities of elderly people do not necessarily differ from those of other demographic groups. It is the specific combination of perspectives, societal attitudes, and individual competencies that may give rise to processes of exclusion. A number of interviewees were rather optimistic about the trickling down of use of ICT tools. They hinted at the traditional diffusion approach in which diffusion of technological artifacts is seen as a process that starts with 'innovators', continues with the 'early adopters', goes on to the 'late adopters', and ends with the 'laggards'. This approach presupposes that the problem of diffusion is merely a problem of reaching a critical mass. Once a significant proportion of users is reached, the majority will follow. The informatization of society is, however, a process that is more complicated than a simple diffusion of artifacts. First, it is a combination of technological and social (organizational) innovations. Everything changes at the same time, and all changes influence each other. Second, it is not the mere use of an artifact but especially the significance of an artifact in a specific constellation that counts. The constellation may change rather rapidly (for instance, at the end of a career) or turn out to be useless for specific categories of users. Finally, the technological base is innovating with enormous speed, which confuses the traditional diffusion process. Before an artifact reaches a mature state it may have been overruled by the next artifact or a competing one. Laggards will remain laggards and will only experience a growing distance from the majority of users. We should not expect the information society to be the simple sum of technological innovations in which processes of change can be explained by following technological trajectories. It will be the total of socio-technical innovations, indicating the intrinsic interdependence between the social and the technological changes that occur today.

Taking the combination of elderly people, exclusion processes, and informatization processes, it seems that specific societal constraints (collective societal norms) are disadvantageous for elderly people. The most important constraint is the statement that elderly people do not have to participate. From this, it follows that - where participation is linked to modern technological developments - they are not able to participate because they lack knowledge and interest in new technologies. In the end, this leads to the conclusion that they do not want to participate.

The way out is not simple. It is mostly beliefs and self-fulfilling prophecies that underlie the feelings of exclusion. Many of these beliefs do not stand a proper second look, for instance, the fact that elderly people are not able to use a computer. Or the fact that they do not want to use email or other forms of electronic communication. When the added value is visible (for instance, the opportunity to receive pictures of relatives via electronic networks), elderly people will be among the first to use the new tools. With respect to societal participation, we conclude that it is not the elderly but the public authorities that are at stake. 
Most of the informatization processes are directed at bringing order in their own backyard, while initiatives are launched that try to improve the information relationship with the citizen. Whether these initiatives cover civilian rights as much as civilian obligations must be doubted. The internal requirements - guided by the hierarchical approach of informatization - are, for the time being, more important than the external relationship (the empowering of citizens). Elderly people are generally seen as care-dependent, and only interested in issues related to safe housing and health care. We think we know what is best for them. And that is a peculiar thing, because, as one interviewee noted: 'We all know what it is to be young, because we all have been young. But who of us has been old?'

\section{REFERENCES}

Adler, R. 1996. Older adults and computers: report of a national survey. www.seniornet.com Dordick, H. S. and Wang, G. 1993. The Information Society - a retrospective view. Sage Publications, London.

Kanters, E. and Hartkamp, F. 1995. The Elderly and Information Technology in Rotterdam.

Onderzoekprogramma vakgroep Sociologie en Sociale Gerontologie, Vrije Universiteit Amsterdam, 1995 (Research programme Department of Sociology and Social Gerontology, Free University of Amsterdam, The Netherlands).

Timmermans, J. 1993. Rapportage Ouderen, SCP, Den Haag (Report on Elderly People).

Timmermans, J. (ed.) 1997. Rapportage Ouderen, SCP, Den Haag (Report on Elderly People).

Van Rijsselt, R. and Weijers, T. 1997a. Uitsluiting van ouderen - de dreiging verkend; evaluatierapport, Rathenau Instituut, Den Haag (Exclusion of elderly people - the threat analyzed; evaluation report).

Van Rijsselt, R. and Weijers, T. 1997b. Ouderen en de informatiesamenleving: een verkenning van opvattingen over aan - en uitsluiting (The Elderly and the Information Society: a survey of attitudes on in - and exclusion). Otto Cramwinkel Uitgeverij, Amsterdam.

Willems and Van den Wildenberg 1996. Haalbaarheidsstudie 'Ouderen en de elektronische snelweg', Den Haag (A feasibility study 'The Elderly and the Electronic Highway').

Zuurmond, A. 1994. De infocratie - een theoretisch en empirische heroriëntatie op Webers ideaaltype in het informatietijdperk, Phaedrus, Den Haag (The infocracy - a theoretical and empirical reorientation on Weber's idealtype in the Information Age). 